\title{
Alta Hooker, galardonada en América Latina por la UNESCO
}

\section{Resumen}

\section{Carlos Manuel Flores ${ }^{1}$}

\begin{abstract}
lta Hooker Blandford, Rectora de la URACCAN fue galardonada por su destacada labor en benefiAcio de la responsabilidad social, territorial y la interculturalidad, impulsada en América Latina. La Organización de las Naciones Unidas para la Educación, la Ciencia y la Cultura (UNESCO) le otorgó la meritoria orden "Ojo de Plata" otorgado por el Observatorio Regional de Responsabilidad Social para América Latina y el Caribe (ORSALS) de la UNESCO, mediante el Instituto Internacional para la Educación Superior de América Latina y el Caribe (IESALC). El galardón fue entregado por Peter Wells, director de Educación Superior de la UNESCO, en el marco del IV Foro Regional: Tendencias de la Responsabilidad Social Territorial en América Latina y el Caribe, en Cartagena de Indias (Colombia).
\end{abstract}

Palabras clave: Orden Ojo de Plata; promoción derechos humanos; responsabilidad social territorial.

\section{Summary}

Alta Hooker Blandford, Rector of the URACCAN, was award for her outstanding work in favor of the social, territorial and intercultural responsibility, promoted in Latin America. The United Nations Educational, Scientific and Cultural Organization (UNESCO) awarded her with the meritorious distinction "Ojo de Plata" granted by UNESCO's Regional Observatory of Social Responsibility for Latin America and the Caribbean (ORSALS), through the International Institute for Higher Education in Latin America and the Caribbean (IESALC). Peter Wells, Director of Higher Education at UNESCO, presented the award, in the framework of the IV Regional Forum: Tendencies in Social Territorial Responsibility in Latin America and the Caribbean, in Cartagena de Indias, Colombia.

Keywords: Ojo de Plata award; promotion of human rights; social territorial responsibility.

T a comunidad internacional de los pueblos indígenas y afrodescendientes del Caribe de América Latina Lhacen suyo este reconocimiento a la rectora Alta Hooker en la promoción de los derechos humanos y la experiencia para estos logros tan importantes en la identidad intercultural. La Universidad de las Regiones Autónomas de la Costa Caribe Nicaragüense (URACCAN) se ha convertido en una institución referencial de estudios superiores donde más de 8,00o personas originarias del Caribe de Nicaragua, han egresado de las diferentes carreras que oferta, ya son 22 años generando cambios en las Regiones Autónomas, y 8 años de trabajo en conjunto con las Universidades Indígenas Interculturales de Abya Yala o América Latina, donde los jóvenes costeños e indígenas sin distinción alguna se empoderan de nuevos conocimientos para aportar al desarrollo justo e integral de sus pueblos.

El premio "Ojo de Plata" es la distinción anual que después de un seguimiento y aplicación de indicadores, visitas técnicas y otros estudios referenciales comparados (benchmarking), se otorga a la entidad que promueve la responsabilidad social territorial no como un bien de mercado, sino como principio solidario de crecimiento equitativo de personas y comunidades.

Dicho reconocimiento está enmarcado en los temas capitales del Observatorio Regional de Responsabilidad Social para América Latina y el Caribe, ORSALC: Patrimonio, Educación, Ciudadanía, Equidad, Medioambiente y en las características e indicadores sobre: Buen gobierno, clima laboral, informes de gestión, voluntariado, medioambiente y campus sostenible —aprendizaje de servicioInvestigación con vocación comunitaria, cultura juvenil, sector productivo y ética social; comités de ética social, desarrollo local y regional, rehumanización. Este reconocimiento se suma a la lista de otras distinciones y reafirma a la URACCAN en su trayectoria que ha emprendido desde el Caribe de Nicaragua y trasciende a los pueblos de América Latina y el mundo, en el aseguramiento a la calidad de la Educación Superior Intercultural.

\footnotetext{
Master en Comunicación Intercultural. Director de Divulgación de la URACCAN de la Universidad de las Regiones Autónomas de la Costa Caribe Nicaragüense email: divulgacion@uraccan.edu.ni
} 